\title{
'I can always rely on them': the importance of social support for boys with haemophilia
}

\author{
Kate Khair*, Faith Gibson*, Liz Meerabeau+
}

Background: Little is known about where, and from whom children with haemophilia receive support, as there is a paucity of psychosocial research on this topic. This paper, part of a larger study of living with haemophilia, discusses the importance of social support for boys with haemophilia.

Methods: Data were collected from 30 boys aged 4-17 years with severe haemophilia A or B from a single Haemophilia Comprehensive Care Centre in the United Kingdom. Age appropriate participatory qualitative research techniques: photo-elicitation, draw and write, focus groups and individual interviews were used. All data were transcribed and the content was analysed using grounded theory.

Results: Social support was gained in many ways from individuals who were identified by the study participants as supportive. These included parents, siblings (affected themselves or not), family members (who may also be affected) and friends. Being able to share experiences with others was also described as supportive.

Conclusion: The boys in this study described many sources of social support, which changed over time as they grew older. Commentary, J Haem Pract 2014;1(1):23.

Key words: social support, haemophilia, boys, young people

Historically boys with haemophilia would spend many weeks in hospital, on bed rest receiving plasma infusions. This resulted in extended periods of school nonattendance. Despite the creation of a boarding school in the UK specifically for boys with haemophilia, they spent prolonged periods in the school hospital because of bleeding and as a consequence had poor educational achievement, resulting in adults with no qualifications who were dependent on relatives and the State for financial and physical support [1]. The boys who attended this school are now in their 40s 50s, and 60s. Despite the separation from home, and the bleeding, pain and disability they experienced, they described the school as a place where 'they were all in it together' and where there was great camaraderie and support (personal communication with ex-residential school pupils).

These days boys receive prophylactic therapy at home

*Great Ormond Street Hospital for Children NHS Trust, London +University of Greenwich, London

Corresponding author: Kate Khair, Nurse Consultant Haemophilia, Great Ormond Street Hospital for Children NHS Trust, London WC1N 3JH. Email: kate.khair@gosh.nhs.uk

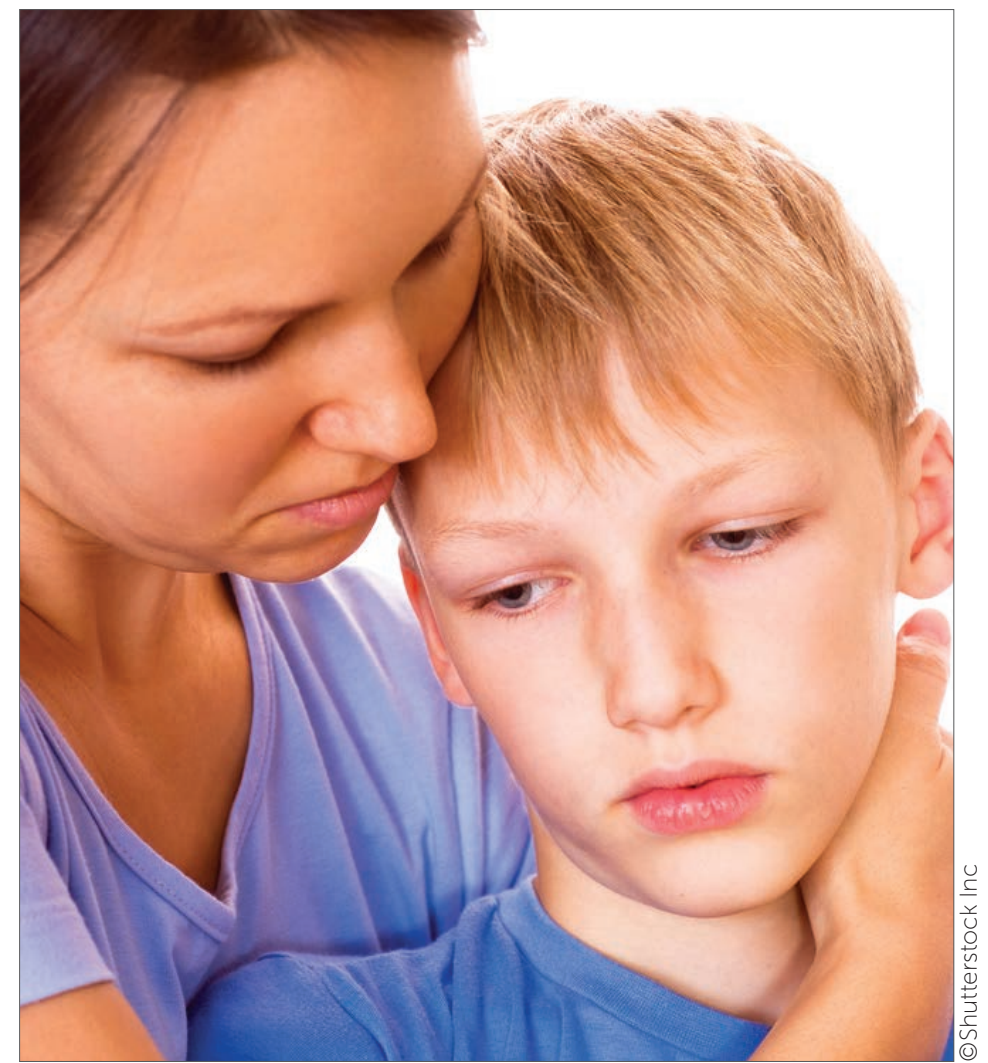

For children the support network is usually, at least initially, close family members

from a very early age [2]; this has reduced bleeding and disability [3] to the point where near normal quality of life has been demonstrated [4]. These boys, who live apparently 'normal' lifestyles, experience bleeds only related to trauma (usually following sport), and have very few restrictions on their life. Attending mainstream school is the 'norm' where they are encouraged to experience everything that their peers do; however they describe both social and geographical isolation from others with haemophilia, and the need for further peer-to-peer education and support [5].

Emiliani et al [6] describe a process of 'normalization' within families affected by haemophilia. In a small study of Italian families they describe how families use strategies such as 'disease acceptance', 'organisation of treatment', 'maintaining a daily routine' and 'communicating and sharing information within the family' to support the whole family in functioning 'in a new way in the presence of haemophilia'. Parents are, they suggest, most important in constructing this 'normality in everydayness' within the 
extended family. This enables the child to interact with family members and peers as a 'normal' individual.

This paper discusses where boys with haemophilia obtain social support, which has been defined as the giving of information to a loved one to demonstrate that $s /$ he is cared for, esteemed and valued. This can be expressed structurally through integration (through support networks) or functionally (by offering tangible emotional support) [7]. Social support is a strategic concept in understanding the maintenance of health and prevention of ill health. It is closely related to the concept of social networks; ties to family, friends, neighbours, colleagues, and others of significance [8].Woodgate [9] described social support as a 'complex phenomenon requiring an individual to believe that they are cared for within a network of support givers'. Support givers may be parents [10], health care workers [11], siblings [12], other family members [9], friends [13] and the Internet [5, 14].

Uchino [15] describes a life-span theory of perceived support and social integration. For small children the support network is usually, at least initially, close family members. As children develop both physically and socially they establish their own support mechanisms through friendships, school, and clubs, and some with ill health belong to a larger community of affected individuals. This may be through face-to-face meetings or on-line relationships developed through social networking channels with others who are also affected $[5,13,16]$.

Little psychosocial research has been undertaken with children with haemophilia since the early 1990s, when many were diagnosed with blood borne viral infections (HIV and hepatitis C). At that time children knew little about their haemophilia [17], were physically incapacitated by it [18], and psychologically affected by HIV infection [19]. This paper addresses social support of children with haemophilia born since the mid 1990s; treatment is now aimed at bleed prevention, using recombinant coagulation factors where the risk of viral infection has been eliminated. This study therefore concerns a very different cohort of children from those treated in the past, who may as a result require different psychosocial support than their predecessors.

\section{Materials and methods}

The study was undertaken at a single haemophilia comprehensive care centre for children in the UK. The sample was a convenience sample from a centre where haemophilia is treated more proactively than in some other parts of the UK or elsewhere in the world; purposeful sampling was also undertaken in that equal numbers of boys from three different age groups were included. Fortysix boys aged 4-16 were invited to participate; thirty boys with severe haemophilia $A(n=27)$ or $B(n=3)$ participated at which point data saturation was achieved as no new findings were emerging. There were ten boys in each age cohort. Half of the boys had a family history of haemophilia with an affected grandfather $(n=5)$, uncle $(n=3)$, older brother $(n=4)$, or multiple family members $(n=3)$. All of the boys received prophylactic therapy and were able to participate fully in family, school and peer led activities [20].

The study was informed by grounded theory [21], since data collection and analysis through close reading and coding of the data took place simultaneously, although this paper reports on data which support an existing concept, that of social support, rather than generating a new concept. It is an example of a key strand of grounded theory, namely a study of how people with a long-term condition manage their lives.

\section{Ethical aspects}

Ethical approval to undertake this study was granted by a National Health Service Research Ethics Committee (study number 08/H1102/67); ethical aspects included avoiding coercion, since the lead researcher was also involved in care giving. Parental consent and patient assent were obtained from all participants at study entry.

\section{Data collection}

Data collection was carried out by the lead author between March and September 2009. The younger cohorts of boys, using photo elicitation [22] for the 4-7 year olds and draw and write techniques [23] for the 8-12 year olds, were given digital cameras, or 'art packs' two weeks before having individual interviews in their own homes. The photographs, drawings or written stories were used as ice breakers and an aide-memoire to enhance discussion about their lives in the preceding two weeks. The interviews, which lasted between 20 and 60 minutes, were semi-structured and tape-recorded, allowing the researcher to give full attention to the interviewee, and what he was saying or doing at the time.

Five boys aged 13-16 attended a focus group [24], which took place in the school holidays in a hotel near the hospital. Open ended prompt questions, such as 'can you tell me what it is like to (experience something?)' and 'other boys have said (something) has that ever happened to you?' were used to elicit their views of life with haemophilia. A further five boys in this age group who were unable to attend the focus group were interviewed alone at home.

The tape recordings from the focus group and the individual interviews were transcribed verbatim by a professional transcriber, and listened to repeatedly by the lead researcher before analysis and coding by hand. The three researchers reviewed the texts and agreed the individual codes, the categories and the overarching concepts that emerged from the data. This enhanced trustworthiness and credibility, i.e. how well the codes and categories captured the data [25], and ensured that inconsistencies in data interpretation did not occur. As the lead researcher knew the boys in the study as a provider of 
clinical care, the two co-authors also ensured trustworthiness of the data by testing her interpretations of it. Each interview was analysed as it occurred; this enabled modifications and additions to the semi-structured questions and continued until data saturation within an emerging framework occurred [21]. Further information on the methodological aspects of this study has been published elsewhere [26].

As discussed above, the content of the narratives was identified and coded into categories. Further analysis of these categories revealed two overarching concepts of managing daily life: data on the first, expert patient skills, will be published elsewhere. The data on the second, social support, are presented in this paper. Representative quotations have been used throughout this text to illustrate the findings; pseudonyms have been used to protect identity.

\section{Results and discussion}

\section{Parents ...'they keep a watchful eye'}

Coyne and Harder [27] describe how children receive advice and guidance throughout their childhoods from parents; a position that does not alter with illness, as children value parental support, when making health care choices. Haemophilia is a disease that affects parents either directly, through carrying the haemophilia gene, or indirectly through living with an affected family member [26]. Support from families has been identified by children and adolescents as being critical in helping them get through life; making the 'right decisions and choices', and helping them through 'difficult and stressful times' [29] and in developing their identity and competence [10]. Twelve year old Michael, who has severe haemophilia A and lives in a rural community, described his parents as too protective:

"They want me to take my phone everywhere I go and just generally stuff like that, my friends don't, not if they are just going down the road or something."

And yet he recognised the need for this support stating:

"It's to make sure I am safe because if I had an accident and I wasn't with any of my friends or anything then I could phone them" [his parents]

Children with haemophilia can be described as more reliant or dependent on their parents [6, 12, 30], however Woodgate [9] describes increased closeness in families of adolescents with cancer, not as loss of independence of the children but more of an interdependence between family members This was demonstrated through an appreciation by adolescents of what family members did for them by 'being there' when needed, but also by 'being there' themselves when they were needed by, or could help others. With genetic disease where a parent is the carrier of the genetic abnormality there is sometimes a feeling of self-blame and therefore of responsibility to ensure treatment is given [31] enhancing interdependence between mother and son as described by Oliver aged 14:

"Neither of my parents really nag, they remind me that I've got to do it [treatment] occasionally if I forget then they just remind me the next day and I will do it then ... they keep a watchful eye. My mum has always taken the role rather than my dad, cos her dad had it [haemophilia] too - so she knows more about bleeds and joints and stuff."

However as boys become more expert at their disease and treatment they can become irritated by what they perceive as adult interference in their lives:

"I am different but I want to be treated a bit more, well there's no normal, but what the phrase people think of as in normal. Like as someone who can just play football, I don't need people watching over me l just want to be treated like other people," (David aged 13).

Parents of children and adolescents with long-term illness develop dynamic and adaptable medication management roles as their adolescent children become more able to self-medicate [32]. This partnership in haemophilia medical care is seen in parents who develop 'mastery' of haemophilia, developing a strong bond, seen as a positive experience for them of having a child with haemophilia [30]. Women can also be seen as the 'genetic housekeepers' and 'kinkeepers' who orchestrate relationships between those who are affected clinically as well as those affected by being part of a haemophilia family [33,34]. Those women and families who support and educate their children about haemophilia and those who grow up with a brother with haemophilia express strong sibling relationships, which draw on positive experiences of haemophilia. These include: appreciating life more, having a good sense of humour in the face of adversity and sharing timely salient genetic information with others, within their family, at risk of having a baby with haemophilia [18].

For haemophilia families, especially those where there is a no previous family history, this 'show' of normality is difficult, but one could argue not unusual. Most families 'display' (or show) aspects of themselves to the viewing world (friends, family, health care workers) to make them seem like 'recognised normal families'. Finch [35] argues that all families present themselves to others through 'displays' of normality which change through circumstance such as divorce, moving house or illness, and that narratives of life experience are used to display family units and relationships to others. These narratives of family history, often told repeatedly, lead to a feeling of belonging to a family or community that may be distant. Finch [35] suggests that these communities may be of extended 
biological family (perhaps living in different countries) but can equally be a group of people connected through friendship or shared experience. This includes the haemophilia community, which includes affected individuals, their biological family, non-biological family members such as step-parents, friends and others who have haemophilia themselves.

\section{Siblings ... 'I feel a bit protective of him'}

Siblings in haemophilia families may be directly affected by haemophilia, either having haemophilia themselves or knowing (if they are a girl) that they are a carrier of haemophilia and may have affected sons themselves in later life. In this study every participant had at least one sibling: 13 boys had brothers (4 younger, 6 older, 3 both) with haemophilia, 9 had brothers without haemophilia ( 3 older, 4 younger, 2 both), 14 boys had a total of 18 sisters (6 older, 6 younger, 2 both) of whom four were known to be haemophilia carriers, five had not been tested and nine were known not to carry haemophilia.

Within families with haemophilia having more children, even if they also have haemophilia, has a positive impact on the children and family. The children with haemophilia are less protected [6], and develop social skills more readily [12]. In the literature, siblings have been found to be 'more caring, mature, supportive, responsible and independent' [36]; this is supported by statements made about the siblings of the children in this study.

Mark aged 16 described how having an older affected brother had helped him in earlier childhood:

"You know we have this kinda relation thing where, you walk along and you are hobbling a bit and he goes 'oh you've got a bad ankle'. He would always notice and tell me to get a needle [treatment]."

Older brothers with haemophilia are also aware of the impact haemophilia might have on their younger brothers:

"I feel a bit protective of him; I think he might get hurt more, more than [his sister and non haemophiliac brother] - a little bit. He's young as well so I try to stop him from getting hurt from messing about." (lan aged 15)

This shows an altruistic element of sibling life in haemophilia families which is also demonstrated by non-haemophilia siblings:

"I think he is affected, he says he finds it hard sometimes, I think in a way he feels guilty that we [Mark and his younger brother] have haemophilia and he doesn't and he goes out of his way to help us out. He'll do things for me, which are just little things, that mean a lot, he's always stuck close to me, cos of that were a good team. (Mark aged 16)."

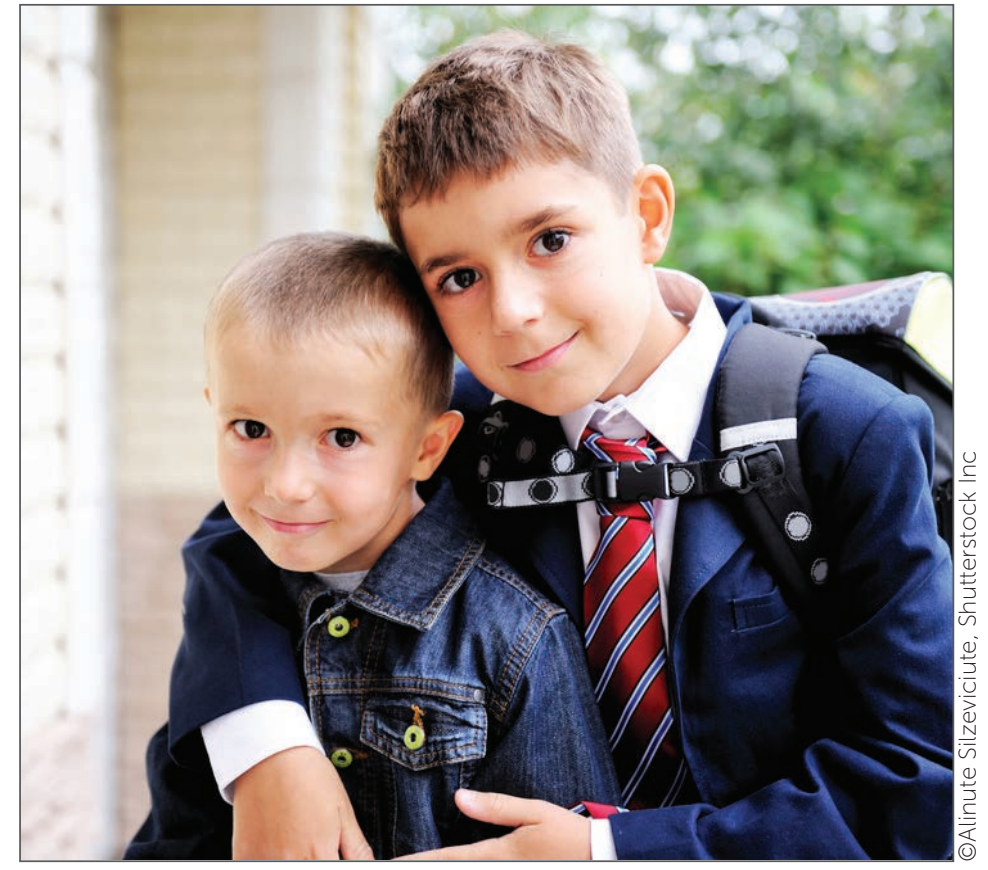

Siblings are often very protective of younger boys affected by haemophilia

This confirms the findings of Barlow \& Ellard [36] that siblings of children with chronic disease are more caring, mature and supportive. However this supportiveness is also seen in boys with haemophilia who demonstrate altruistic feelings towards their non-affected siblings:

"[lt's good he] didn't have it, because he does not have haemophilia cos he is only little. I don't want my brother to have haemophilia so I am better off having it myself." (Nick aged 9)

Such expressions of altruism may also extend to potential future family members:

"She's [his little sister] not a carrier ... they [his parents] had this special treatment, they had like IVF thing and then some special treatment which has never been done before [pre-implantation genetic diagnosis] and it worked so she's not a carrier ... it's a good idea because then it stops that part of the family having haemophilia because [names sister] can go on and have them [babies] they can't get it ever again (Oliver aged 14)."

The role of families in supporting children with genetic diseases within the context of a day-to-day normality of life is important [34]. The children themselves are supportive of each other, with a healthy sibling having a 'positive effect, which reduces parental feelings of guilt and supports the affected child in their day to day activities' [12]. This is confirmed by Peter (aged 14):

"But also even though my older brother doesn't have 
haemophilia, he still encourages me and does those things to help or that he thinks I should do even though he doesn't really know what it's like or but he still gets it."

'Siblings' may not always be biological; George, aged 16, who had been at boarding school since he was twelve described how he has been accepted by his 'school brothers' as being different from them, but when treated he could be just like them:

"I have to go to the med centre, none of the others do, but then it's like got such a big part of my routine now, like every other day I go there at the same time straight after lunch, I say I'm going to the med centre and they know what's going on they don't have to ask - they just know and then I can be just like the rest and do sport and stuff just like they do."

The boys at George's school had become extended family members to him - not biologically related but part of his support mechanism, in essence his everyday siblings who understood him and his needs as his biological family did.

\section{Other affected family members ... 'he is someone I can actually relate to'}

As well as having affected siblings, several boys had other affected family members such as uncles and grandfathers, who being at least a generation older and having grown up in the era of blood-borne infection had different views of haemophilia care and self-management. These views may include treating bleeds only once they have occurred, thus avoiding exposure to factor, which is seen as something to be given only when absolutely necessary. This may be confusing to younger boys such as 9 year old Nick:

"I sometimes talk to uncle [name] about having haemophilia and he says ... well he always says something different mostly. He is normally in his room so I don't get to see him that much ... he has got a walking stick and that's it ... he's not much help really 'cos not everyone is the same are they? Even with haemophilia not everyone's the same he doesn't get injections much so I can't talk to him about that even."

Conversely older boys found more benefit from older family members who were able to share histories and experiences, which instilled a feeling of 'not being in it alone' (James aged 13). Sixteen-year-old Mark described significant benefits of having an older affected cousin:

"I've got a cousin who is about 42-ish and we go and play cards, and he's got haemophilia and we generally chat. I think I look to him for a friend because he is older and he has lived with it [haemophilia] longer than me, then we have a discussion about it which is ... and I might go through exactly the same so that means quite a lot. He is someone I can actually relate to on a level where they know where I am coming from I suppose."

This sense of gaining support from other affected people, those who 'really know' is one shared by many children and young people with long term illness. Ravert and Crowell [14] describe how adolescents with cystic fibrosis frequently express 'psychosocial concerns' and enlist 'social support' amongst an Internet-based cystic fibrosis community. The adolescents in Ravert \& Crowell's study state that disease awareness and life experience are important for support. This is further supported by The Guardian [37] publication stating that shared experience on the Internet 'fosters a sense of social support' particularly for people with chronic illness. Sterling et al [16] and Khair et al [5] describe how the Internet can be used by children and adolescents to communicate with others who also have haemophilia. This is particularly important for: boys who are the first in their family to be affected, those who are the first to be born into families where older affected relatives have died and those who are geographically isolated and have little contact with others. These boys have identified a need for peer-to-peer education and support [5] from boys older than themselves. The Internet extends their haemophilia family into the wider haemophilia community - a grouping of those affected by, who carry and who treat haemophilia.

Petersen [18] describes how a sense of belonging to the 'greater haemophilia community' provides positive attributes for those affected by haemophilia including: an appreciation of life, a sense of humour and being a 'layexpert', which promotes a better life. Within the haemophilia community beneficial friendships with others who are similarly affected can be established.

\section{Friends... 'He doesn't care what others say, he's just my friend'}

Friendship, a mutual bond and understanding between two or more people, is a key aspect of social development. For boys with haemophilia, school may be the first time they are away from the care of immediate family members and are starting to develop lifelong friendships. Their diagnosis may be revealed to others for the first time, by their parents, to ensure their safety in, for example, the school environment. Sometimes in older boys this causes discord with their parents as they do not always want their friends and peers to know about haemophilia as they perceive this makes them different. With some chronic illnesses the differences are harder to hide due to obvious signs, such as seizures in children with epilepsy [38], whereas with haemophilia it would only become apparent if joint bleeds occurred or boys needed to use mobility aids.

Best friends are important for children; those they are most comfortable with and those with whom they are 
most likely to discuss their health [29], illness [39], girl/boyfriends, careers and futures. Best friends provide support in many aspects of life, often in adversity. Nick (aged 9) said:

'I can always rely on them, they are always kind to me and when I fall over they always help me up and I can play with them a lot'.

Will (aged 10) described how his best friend supported him:

"He is always the one that stays on my side and like helps me ... sometimes because of my hair (which is wild and frizzy and for which he gets teased at school) and sometimes because of haemophilia. But he doesn't care what the others say he just stays my friend."

Older boys were happy to self-infuse in front of their friends unless their friends didn't like this: 'I do my injections if my friends stay round my house but a lot of my friends don't like needles so they just go out of the room' (Peter aged 14). The acceptance of haemophilia by best friends is particularly important for adolescent boys who are embarking on relationships with girls. Those who have had supportive friendships find it easier to tell girls that they have haemophilia at an appropriate stage of the relationship. Fourteen year old Peter described how he decided when to tell girls about his haemophilia:

"When you're trying to impress a girl I suppose it's the only thing you don't want to come out with straightaway and let yourself down a couple of notches you have to start on a fair level but it's important that they know."

Oliver, also aged 14, was more open about his haemophilia, and wearing a Medic Alert bracelet drew attention to it:

"I've had quite a few [girlfriends] and they all know cos they always ask 'what's that bracelet' and I just tell 'em ... it doesn't bother me, it's nothing to be honest, it's nothing at all, and they need to know if they're gonna be around."

Friendship, with peers and others with haemophilia (perhaps via social support sites on the Internet) supports boys with haemophilia in developing into adolescence and adulthood as rounded individuals who feel cared for and valued as 'normal' members of society. Contemporary treatment has made this easier for boys today as they attend mainstream school and participate in sport and other activities, previously deemed too dangerous for them.

\section{Conclusion}

The overall aim of the study, from which this paper is drawn, was to discover what it is like to live with haemophilia in the twenty-first century, where intensive treatment has, from a medical perspective normalised the lives of affected boys [3,4]. Analysis of the data identified the importance of social support, discussed in this paper. A strength of the study was the lead researcher being a haemophilia clinician and having an understanding of haemophilia care, its impact on children and young people and recognising that there were psychosocial impacts of haemophilia care which were not being addressed through routine medical care and follow up, although it is recognised that her dual role may have increased selfpresentation by participants as 'normal families' as discussed earlier. The boys in this study perceived themselves as 'normal' children participating in life equally to their peers and siblings who they identified as a key component in their support networks.

Support is gained from many sources including parents, siblings, family, the Internet and others with haemophilia. Shared experience can be obtained from family members [18], and the extended haemophilia community through face-to-face meetings or on-line support via the Internet. The latter is a social support tool for most adolescents in the UK who use it, often daily, to communicate with friends and family and recent research $[5,16]$ has identified it as an important source of support for adolescents as they become more sufficient in self-management, sharing tips and ideas.

Little work has previously been carried out with children or adolescents about living with haemophilia in an era of better treatment and less restricted lifestyles, suggesting that further studies with children and adolescents to foster continued understanding between health care providers and recipients are necessary. Disease specific quality of life assessment instruments are used in clinical practice; these show good treatment outcomes but do not accurately reflect the day-to-day reality of life with haemophilia for children and adolescents. Beginning to hear about experience is important as this enables health care professionals to better understand the issues that they are living with today, and to ensure they receive appropriate support. To improve clinical care, we have recently introduced questions into routine clinical review about where children gain social support; these ask about friends and who they talk to about haemophilia, and the use of social media including the new social network for children with bleeding disorders. Quality of life assessments, which include questions about social support, are also now being used as outcome measures and are being undertaken at annual reviews.

This study is limited in that it was undertaken in a single centre in the UK, therefore the results of the study cannot be extrapolated to all children and young people with haemophilia, particularly since haemophilia is very actively managed at this centre, minimising joint damage. Further work is necessary to confirm and extend these findings; in particular, theoretical sampling by including a centre 
where haemophilia is not so actively managed would be valuable and in keeping with grounded theory. This study confirms the need to ask children and young people about their experiences, listen to what they have to say, and be consistent over time in collecting such data so that changes in health outcomes continue to shape how we support young boys with haemophilia.

\section{Acknowledgement}

The research was funded by Bayer Healthcare Pharmaceuticals Haemophilia Caregiver's Educational Award. The authors wish to thank the boys who took part in this study.

\section{References}

1 Jones P. Living with Haemophilia. Fourth edition (1995). Oxford University Press. 2 Khair K. Managing haemophilia at home. Br J Home Healthcare 2006; 1: 10-11. 3 Liesner R, Khair K, Hann IM. The impact of prophylaxis on children with severe haemophilia. Br J Haematol 1996; 92: 937-38.

4 Gringeri A, von Makensen S, Auserwald G, Bullinger M, et al. Health status and health related quality of life of children with haemophilia from six west European countries. Haemophilia 2004; 10:1,26-33.

5 Khair K, Holland M, Carrington S. Social Networking for Adolescents with Severe Haemophilia. Haemophilia 2011: 18(3): e290-6.

6 Emiliani F, Bertocchi S, Poti S, Palaretu L. Process of normalization in families with children affected by hemophilia. Qual Health Res 2011: 12:1667-78

7 Rrishnaswamy M. Social support and the patient with cancer: a consideration of the literature. J Adv Nursing 1996; 23: 757-62.

8 EUPHIX. http://www.euphix.org/object_document/05478n27411.html last accessed 28th August 2011.

9 Woodgate RL. The importance of being there: perspectives of social support by adolescents with cancer. J Ped Onc Nursing 2006; 23: 122-34.

10 Paterson B, Brewer J. Needs for social support among parents of adolescents with diabetes. J Nursing and Healthcare of Chronic Illness 2009; 1: 177-185. 11 Kyngas H, Hentinen M, Barlow J, et al. Adolescents' perceptions of physicians, nurses, parents and friends: help or hindrance in compliance with diabetes selfcare? J Adv Nursing 1998; 27: 760-69.

12 Clemente C, Tsiantis J, Kolvin I, et al. Social adjustment in three cultures: data from families affected by chronic blood disorders. A sibling study. Haemophilia 2003; 9: 317-24

13 Bokhorst C, Sumter S, Westenberg M. Social support from parents, friends, classmates and teachers in children and adolescents aged 9 to 18 years: Who is perceived as most supportive? Social Development 2010; 19(2): 417-26.

14 Ravert R, Crowell T. 'I have cystic fibrosis': an analysis of web-based disclosures of a chronic illness. J Nursing and Healthcare of Chronic Illness in association with J Clin Nursing 2008; 17: 318-28.

15 Uchino B. Understanding the link between social support and health: A life-span perspective with emphasis on the separability of perceived and received support. Perspectives on Psychol Sci 2009; 4: 236-55

16 Sterling L, Nyhof-Young J, Blanchette VS, Breakey VR. Exploring internet needs and use among adolescents with haemophilia: a website development project. Haemophilia 2011; 18(2): 216-12

17 Spitzer A. Children's knowledge of illness and treatment experiences in 17 Spitzer A. Children's knowledge of illness

18 Petersen A. The best experts: the narratives of those who have a genetic condition. Soc Sci Med 2006; 63: 32-42

19 Logan F, Maclean A, Howie CA, et al. Psychological disturbance in children with

haemophilia. BMJ 1990; 301: 1253-6. with severe haemophitia. Haemophilia 2011; 18(3): e266-9.

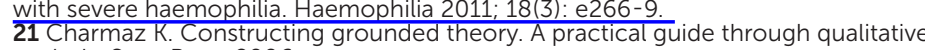
analysis. Sage Press 2006

22 Clark C. The autodriven interview. A photographic viewfinder into children's experience. Visual Sociol 1999; 14: 39-50.

23 Horstman M. Aldiss S, Richardson A et al. Methodological issues when using the draw and write technique with children aged 6-12 years. Qual Health Res. 2008; 18(7): 1001-11.
24 Gibson F. Conducting focus groups with children and young people: strategies for success. J Nursing Res. 2007; 12: 473-83.

25 Graneheim UH, Lundman B. Qualitative content analysis in nursing research: concepts, procedures and measures to achieve trustworthiness. Nurse Ed Today 2004; 24: 105-112.

26 Khair K, Collier C, Meerabeau L, Gibson F. Multi-methodology research with boys with severe haemophilia. Nurse Researcher. Nurse Res 2013; 20(6): 40-4.

27 Coyne I, Harder M. Children's participation in decision making: Balancing protection with shared decision-making using a situational perspective. J Child Health 2011; 15(4): 312-9

28 Khair K, Gibson F, Meerabeau L. 'Just an unfortunate coincidence': children's understanding of haemophilia genetics and inheritance. Haemophilia 2011; (17): 470-75.

29 Woodgate RL, Leach J. Youth's perspectives on the determinants of health. Qualitative Health Res 2010; 20: 1173-82

30 Beeton K, Neal D, Watson T, Lee C. Parents of children with haemophilia - a transforming experience. Haemophilia 2007; 13: 570-79.

31 Ross J. Perspectives of haemophilia carriers. Haemophilia 2000; 6: 41-45 32 Newbould J, Smith F, Francis SA.'I'm fine doing it on my own:' partnerships between young people and their parents in the management of medication for asthma and diabetes. J Child Health Care 2008: 12: 116-128.

33 Thomas S, Herbert D, Street A, et al. Attitudes towards and beliefs about genetic testing in the haemophilia community: a qualitative study. Haemophilia 2007; 13: 633-41.

34 Gregory M, Boddington P, Dimond R, et al. Communicating about haemophilia within the family: the importance of context and experience. Haemophilia 2007; 13: 189-198.

35 Finch J. Displaying families. Sociology 2007; 41(1): 65-81.

36 Barlow J, Ellard D. The psychosocial well-being of children with chronic disease, their parents and siblings: an overview of the research evidence base. Child: Care, Health \& Dev 2005; 32(1): 19-31.

37 The Guardian 09/05/2011 Social network users have twice as many friends online as in real life. http://www.theguardian.com/media/2011/may/09/socialnetwork-users-friends-online last accessed 16th December 2013.

38 Eklund PG, Sivberg B. Adolescents lived experience of epilepsy. J Neurosci Nursing 2003; 35: 40-49.

39 Gallo AM, Schulz VH, Breitmayer BJ. Description of the illness experience of adolescents with chronic renal disease. ANNA Journal 1992; 19: 190-214.

\title{
The Journal of Haemophilia Practice
}

\author{
An open-access journal for sharing experience \\ in the care of people with bleeding disorders
}

www.haemjournal.com 